\title{
Bioanalytical RP-HPLC method validation for resveratrol and its application to pharmacokinetic and drug distribution studies
}

\author{
Shivaprasad Gadag ${ }^{1}$, Reema Narayan ${ }^{1}$, Yogendra Nayak ${ }^{2}$, Usha Yogendra Nayak ${ }^{1 *}$ \\ ${ }^{1}$ Department of Pharmaceutics, Manipal College of Pharmaceutical Sciences, Manipal Academy of Higher Education, Manipal 576104, Karnataka, India \\ ${ }^{2}$ Department of Pharmacology, Manipal College of Pharmaceutical Sciences, Manipal Academy of Higher Education, Manipal 576104, Karnataka, India.
}

\begin{tabular}{l}
\hline ARTICLE INFO \\
\hline Received on: 03/08/2021 \\
Accepted on: $13 / 10 / 2021$ \\
Available Online: 05/02/2022
\end{tabular}

\section{Key words:}

Bioanalytical method, resveratrol, pharmacokinetics, tissue distribution, HPLC.

\begin{abstract}
In the present study, an attempt was made to develop and validate a highly sensitive reverse phase-High Pressure Liquid Chromatography (HPLC) method for the quantification of resveratrol (RVT) in the plasma and tissue matrix. Pharmacokinetics and tissue distribution studies were carried out in rats after oral administration of RVT. RVT was eluted using $0.1 \%$ orthophosphoric acid and acetonitrile as the mobile phase. The developed method showed good recovery and linearity without any interference from the biological matrix. From the pharmacokinetic studies, the plasma half-life of RVT was found to be $4.4 \pm 0.12$ hours. It was observed from bio-distribution studies that RVT preferentially accumulated in the high perfused organs. The developed method was successfully applied for the quantification of RVT in different biological matrices.
\end{abstract}

\section{INTRODUCTION}

Resveratrol (RVT) is a polyphenol abundantly present in the roots of Polygonum cuspidatum, berries, grapes, and peanuts (Ndiaye et al., 2011). Studies have proven that RVT possesses many biological activities which include analgesic, delaying aging, antitumor, vasodilation, antioxidant, inhibition of platelet aggregation, anti-inflammatory, neuroprotective, antidiabetic, and antiobesity (Fiod Riccio et al., 2020; Salehi et al., 2018; Szkudelska et al., 2014). The anticancer activity of RVT studied on cancer cell lines (T47D and MCF-7), and in breast cancerinduced animal model, has demonstrated its chemotherapeutic potentials (Bishayee, 2009; Fiod Riccio et al., 2020; Sinha et al., 2016). Despite the proven therapeutic efficacy, the use of RVT is restricted owing to its low bioavailability and its rapid metabolism and elimination from the body (Ethemoglu et al., 2017).

The information available on the pharmacokinetic and tissue distribution of RVT is limited, despite the numerous literature studies

\footnotetext{
${ }^{*}$ Corresponding Author

Usha Yogendra Nayak, Manipal College of Pharmaceutical Sciences, Manipal Academy of Higher Education, Manipal 576104, Karnataka, India. E-mail: usha.nayak@manipal.edu
}

on its potential efficacy. Bertelli et al. (1996) were able to quantify RVT in the plasma and tissues after the administration of red wine to the rats. Emilia et al. (2010) developed a liquid chromatographymass spectrometry (LC-MS) method to quantify RVT along with its metabolites in the plasma and different tissues after the intravenous administration of RVT in rats (Juan et al., 2010b). Santos et al. (2019) reported a $t_{\max }$ of 0.25 hour, $C_{\max }$ of $147.33 \pm 25.81 \mathrm{ng} / \mathrm{ml}$, half life of $1.17 \pm 0.90$ hours, and $\mathrm{AUC}_{0-\mathrm{t}}$ of $224.67 \pm 59.97 \mathrm{ng}$. hour $/ \mathrm{ml}$ with a elimimation rate $(\mathrm{Ke})$ of $0.83 \pm 0.48$ hour $^{-1}$ after a single dose of RVT orally $(20 \mathrm{mg} / \mathrm{kg})$ in Wistar Han rats. RVT showed $20 \%$ oral bioavailability after administration of $50 \mathrm{mg} / \mathrm{kg}$ weight of RVT to rats (Kapetanovic et al., 2011). The pharmacokinetics of aglycon and the glucuronide form of RVT were studied after intravenous administration to rats by Marier et al. (2002) using HPLC. Jagwani et al. (2020) developed the HPLC method for the quantification of RVT in human and rat plasma. Nevertheless, the reported methods failed to quantify lower concentrations $(<20 \mathrm{ng} / \mathrm{ml})$ of RVT in the biological matrix with an acceptable linearity coefficient. To the best of our knowledge, no literature is available on the quantification of RVT at very low concentrations with breast tissue distribution studies upon oral administration of RVT in rats using the Reverse Phase High Pressure Liquid Chromatography (RP-HPLC) method. It is extremely important to quantify RVT in the breast tissue 
and other vital organs to assess the safety and efficacy of RVT used for breast cancer treatment. In the present study, we have developed a novel, highly sensitive, simple, and precise RP-HPLC method for the quantification of RVT in the plasma and different tissue matrices. The developed method was successfully applied for the pharmacokinetics and tissue distribution studies after oral administration of RVT in rats.

\section{MATERIALS AND METHODS}

\section{Materials and reagents}

RVT (99.64\%), caffeine (>98\%), epigallocatechin gallate $(>98 \%)$, and betamethasone $(98.92 \%)$ were purchased from TCI Chemicals, India. HPLC-grade organic solvents, such as methanol, acetonitrile (ACN), and buffer salts such as potassium dihydrogen orthophosphate, sodium dihydrogen phosphate, orthophosphoric acid (OPA), trifluoracetic acid (TFA), etc., were procured from Merck Ltd., India. Methyl tert-butyl ether (MTBE) was purchased from Spectrochem, India.

\section{Instrumentation}

HPLC system of Shimadzu make (LC-2010CHT, Shimadzu, Japan) was used for the analysis and equipped with quaternary pumps, autosampler, UV detector, and a column oven with a degasser unit operated with LC solution 5.57 software.

\section{Preparation of plasma matrix and tissue homogenate}

Ethical approval was taken from the Institutional Animal Ethical Committee, Kasturba Medical College, Manipal, India (Approval no.: IAEC/KMC/33/2017) before the study and Committee for the Purpose of Control and Supervision of Experiments on Animals guidelines were followed during the studies.

\section{Preparation of plasma matrix}

The blood was withdrawn from the rat's retro-orbital plexus and collected into a vial containing anticoagulant $(10 \%$ Ethylenediamine tetra acetic acid (EDTA) and 15\% ascorbic acid). For the separation of plasma, the collected blood was centrifuged at $10,000 \mathrm{rpm}$ for 10 minutes using a microcentrifuge (Spinwin, Tarsons Product Pvt. Ltd., India). The plasma samples were preserved at $-80^{\circ} \mathrm{C}$ until analysis.

\section{Preparation of tissue homogenate}

The rats were anesthetized using diethyl ether $(\sim 4-5 \mathrm{ml}$ via inhalation route) (Aguwa et al., 2020; Plate et al., 2005) and sacrificed humanely, followed by dissecting the animals to collect different organs such as liver, kidney, spleen, breast tissue, lung, and heart. The isolated organs were weighed and then homogenized in $0.9 \% \mathrm{NaCl}$ containing ascorbic acid (Juan et al., 2010a). The final volume of the liver homogenate was $4 \mathrm{ml}$ and that of the remaining organ homogenates was $2 \mathrm{ml}$.

\section{Extraction procedure and chromatographic condition}

Drug and internal standards (IS) were extracted from the plasma/tissue matrix by the liquid-liquid extraction method (Lin et al., 2018; Sanson et al., 2011). To $200 \mu \mathrm{l}$ of plasma/tissue homogenate, $10 \mu \mathrm{l}$ of $10 \mu \mathrm{g} / \mathrm{ml}$ IS was added and mixed with the help of a vortex mixer. Up to $1.8 \mathrm{ml}$ of MTBE was added as the extraction solvent and vortexed for 5 minutes. These samples were centrifuged for 10 minutes at $10,000 \mathrm{rpm}$, followed by the separation of the supernatant into evaporation tubes. The separated MTBE layer was evaporated to complete dryness. After evaporation, the residue was treated with $200 \mu \mathrm{l}$ of $50 \%$ methanol in water as the diluent and mixed thoroughly with the help of a vortex mixer and injected into the HPLC. Phenomenex Kinetics $\mathrm{C}_{18}(250 \times 4.6 \mathrm{~mm}, 100 \AA$ pore size, and $5 \mu \mathrm{m}$ particle size) was used as the stationary phase. Different mobile phases, flow rate, organic phase to aqueous phase ratio, and column oven temperature were tried to optimize the method. The detection wavelength was maintained at $306 \mathrm{~nm}$.

\section{Preparation of quality control samples and spiked samples}

The standard stock solutions of RVT and IS were prepared by dissolving $2.5 \mathrm{mg}$ of RVT and IS, separately in $25 \mathrm{ml}$ of diluent ( $50 \%$ methanol in water), followed by serial dilution of the aliquot with the diluent. High-, mid-, and low-quality control samples (HQC: 1,000 ng/ml, MQC: $500 \mathrm{ng} / \mathrm{ml}$, and LQC: $25 \mathrm{ng} / \mathrm{ml}$ ) were prepared by spiking the known concentration of RVT standard stock solution into plasma/organ homogenate samples. Similarly, RVT standard solution was spiked into plasma/organ homogenate sample to prepare the linearity samples $(10,25,50$, $100,150,250,500$, and $1,000 \mathrm{ng} / \mathrm{ml})$.

\section{Chromatographic method optimization}

To optimize the bioanalytical method, different buffers, $\mathrm{pH}$ 4.5 acetate buffer, $0.1 \%$ OPA, and $0.1 \%$ TFA were tried along with $\mathrm{ACN}$ or methanol as organic solvents. Different chemical compounds such as caffeine, epigallocatechin gallate, and betamethasone were screened as the IS. To quantify a lower concentration of RVT, the injection volume was fixed at $80 \mu \mathrm{l}$. For better recovery of the drug, different organic solvents were used such as MTBE, methanol, ACN, $\mathrm{MTBE}+\mathrm{ACN}$, and MTBE + methanol.

\section{Bioanalytical method validation}

System suitability was assessed by injecting six replicates of $500 \mathrm{ng} / \mathrm{ml}$ concentration samples into the HPLC. To assess the selectivity of the method, blank plasma/organ matrix, diluent, and samples were injected in triplicates into the HPLC. Interference of the biological matrix or diluent at the retention time of RVT and IS was assessed. The linearity of the developed method was determined by injecting samples of different concentrations (10, $25,50,100,150,250,500$, and $1,000 \mathrm{ng} / \mathrm{ml})$. The ratios of RVT and IS were plotted against the concentration of RVT to establish the linearity equation along with the coefficient.

Inter- and intra-batch precision were established by injecting HQC, MQC, and LQC samples $(n=6)$. The \% recovery of RVT from the biological matrix was calculated at HQC, MQC, and LQC $(n=3)$ comparing it with the aqueous standard sample of the same concentration $(n=3)$.

Short-term, long-term, and freeze-thaw stability studies were carried out wherein the HQC and LQC samples were frozen at $-80^{\circ} \mathrm{C}$ for a day and thawed at $25^{\circ} \mathrm{C}$, similarly, the freeze-thaw cycle was repeated thrice, and the samples were analyzed. For short-term stability, HQC and LQC samples $(n=3)$ were kept at room temperature for 24 hours and the samples were analyzed at the end of 24 hours. Long-term stability studies were carried out 
by storing $\mathrm{HQC}$ and LQC samples $(n=6)$ and analyzing them on the 15th and 30th day. Benchtop stability studies for RVT and IS were carried out by keeping the samples at room temperature for 24 hours and the same were analyzed using HPLC.

\section{Application of the method: pharmacokinetics and tissue} distribution study in rats

The developed method was used to analyze RVT in plasma and tissue samples. The pharmacokinetics and tissue distribution studies were carried out following the oral administration of RVT at the dose of $20 \mathrm{mg} / \mathrm{kg}$ in Sprague Dawley rats $(n=6)$.

For pharmacokinetic studies, at predetermined time intervals $(0.08,0.16,0.25,0.33,0.5,1,2,4,8,12$ and 14 hours), blood samples $(\sim 0.5 \mathrm{ml})$ were withdrawn from the retro-orbital plexus and collected in tubes containing EDTA; plasma was separated by centrifugation and the amount of drug was quantified by the developed method using HPLC. Similarly, for tissue distribution studies, at a predetermined time interval $(0.16,1,2,4$, 8 , and 12 hours), animals were sacrificed $(n=6)$, and the organs (heart, spleen, liver, lung, kidney, and breast tissue) were harvested and homogenized, followed by the quantification of RVT in the tissues by the HPLC method.

\section{Statistical analysis}

One-way analysis of variance with post-hoc Tukey's test using GraphPad Prism 5.03 was used to compare the different groups. $p$-value less than 0.05 was taken as significant.

\section{RESULTS AND DISCUSSION}

\section{Optimization of bioanalytical method}

As the pKa of RVT is 8.99, (PubChem. Resveratrol,2021) to avoid the splitting of the peak and to get a single peak, we ensured that the $\mathrm{pH}$ of the buffer was maintained at $<6.8$. For the initial isocratic trials, acetate buffer with $\mathrm{pH} 4.5$ was tried with $\mathrm{ACN}$ as the organic phase in different ratios. In the isocratic method of elution, the peak was found to be broad when the injection volume was increased from 20 to $80 \mu \mathrm{l}$, and the theoretical plate count was below the acceptable limit, i.e., $<2,000$. However, due to the broader peak, it was very difficult to quantify the drug at the lower concentration. Similarly, we tried different buffers such as $0.1 \%$ TFA and $0.1 \%$ OPA with ACN. Out of the various trials, $0.1 \%$ OPA with $\mathrm{ACN}$ as the mobile phase showed a lesser baseline

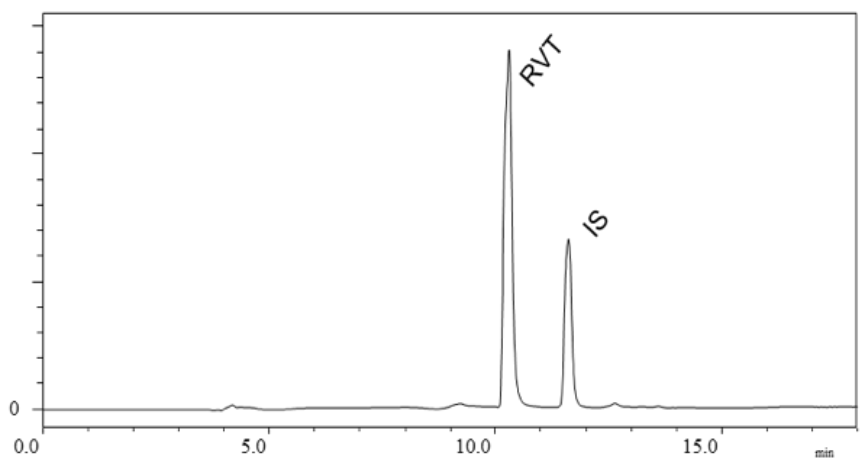

Figure 1. Chromatogram of RVT and IS in plasma obtained from optimized chromatographic conditions.
Table 1. Composition of organic ratio used in the gradient program.

\begin{tabular}{|c|c|c|}
\hline \multicolumn{2}{|c|}{ Time (minute) } & \multirow{2}{*}{$\begin{array}{c}\text { ACN (\%) } \\
10\end{array}$} \\
\hline Start & 2 & \\
\hline 2 & 4 & 10 \\
\hline 4 & 8 & 50 \\
\hline 8 & 10 & 60 \\
\hline 10 & 12 & 10 \\
\hline 12 & 15 & 10 \\
\hline 15 & Stop & 10 \\
\hline
\end{tabular}

Table 2. Results of system suitability.

\begin{tabular}{ccc}
\hline $\begin{array}{c}\text { System suitability } \\
\text { parameter }\end{array}$ & Acceptance criteria & Observed \\
\hline $\begin{array}{c}\text { \% RD of peak area } \\
(n=6)\end{array}$ & $<2.0 \%$ & $1.1 \%$ \\
Tailing factor & $<2.0$ & $1.21 \pm 0.02$ \\
Theoretical plate count & $>2,000$ & $25.067 \pm 243.61$ \\
\hline
\end{tabular}

disturbance with a better peak shape. However, the peak was broader at a lower concentration of RVT. Hence, we attempted the gradient elution method to obtain a sharp peak with an acceptable system suitability parameter. The column oven temperature was kept at $40^{\circ} \mathrm{C}$ to get a better peak shape. The composition and the gradient program of the mobile phase are presented in Table 1.

Different ISs were used to optimize the method. When caffeine was used as the IS, due to its hydrophilic nature, it did not retain in the column and eluted at the void volume. A similar observation was made in the case of epigallocatechin gallate due to its higher polarity. Betamethasone being comparatively less polar than the other two ISs, it was found to elute after RVT peak and the system suitability parameters were found to be within the acceptable limit. Figure 1 shows the chromatogram of RVT in plasma along with the betamethasone as IS for the optimized chromatographic conditions.

\section{METHOD VALIDATION}

The developed bioanalytical method was validated as per the United States Food and Drug Administration (USFDA) guidelines (FDA et al., 2018). The system suitability parameters such as \% Relative Standard Deviation (RSD) of peak area, tailing factor, and theoretical plate count were found to be within the acceptable limits (Table 2). The developed method was specific to the analyte of interest as we did not observe any interference at the retention time of RVT and the IS due to diluent and biological matrix (Fig. 2). The method showed linearity in the range of 10 $1,000 \mathrm{ng} / \mathrm{ml}$; the regression data is shown in Table 3. The Lower Limit Of Quantitation (LLOQ) of RVT in the tissue matrix was $5 \mathrm{ng} / \mathrm{ml}$. The recovery of the drug from plasma and other tissue matrix was within the acceptable limits of $85 \%-120 \%$, which is presented in Table 4. The \% RSD for inter-batch and intra-batch runs was lesser than $15 \%$ for the developed method at HQC, MQC, and LQC. The biological samples were stable after three cycles of the freeze-thaw process (Table 5). The biological samples were stable on short- and long-term storage, indicating that its use till 30 days (stored at $-80^{\circ} \mathrm{C}$ ), after storage did not have any effect on its 
Table 3. Regression data for RVT in plasma and tissue homogenate.

\begin{tabular}{cc}
\hline Tissue & $\boldsymbol{R}^{2}$ \\
\hline Plasma & 0.9991 \\
Heart & 0.9978 \\
Kidney & 0.9979 \\
Liver & 0.9992 \\
Lung & 0.9994 \\
Spleen & 0.9979 \\
Breast tissue & 0.9993 \\
\hline
\end{tabular}

analysis. RVT and betamethasone standard solution was stable for 24 hours with a relative error of less than $2 \%$.

\section{Application of method: pharmacokinetics and tissue distribution studies}

Although literature related to the bioavailability of RVT are available, the knowledge on tissue distribution in all the organs is limited. The reason may be the lack of a sensitive and complete validated method to estimate the low concentration of RVT in the biological matrix. Here, we have attempted to develop a highly sensitive RP-HPLC method to quantify a very low concentration of RVT in different biological matrices and validate the same.

$C_{\max }:$ maximum plasma concentration, $T_{\max }:$ time for maximum plasma concentration, $t_{1 / 2}$ : half-life, MRT: mean residential time, AUC: area under the curve, and $\mathrm{K}_{\mathrm{e}}$ : elimination rate constant.

Data are given as mean $\pm \mathrm{SD}, n=6$.

The plasma RVT concentration versus time profile of RVT after administration of a single oral dose of $20 \mathrm{mg} / \mathrm{kg}$ RVT is shown in Figure 3 and the pharmacokinetic parameters are presented in Table 6. The RVT showed a plasma maximum of $258.6 \pm 30.27 \mathrm{ng} / \mathrm{ml}$ at $0.3 \pm 0.0$ hour which indicated that RVT was rapidly absorbed from the gastrointestinal tract. The half-life $\left(t_{1 / 2}\right)$ of RVT was found to be $4.4 \pm 0.12$ hours with a higher elimination rate constant of $0.16 \pm 0.01$ /hour, which indicates that the RVT gets rapidly metabolized and eliminated as glucuronide conjugate and sulfate (Marier et al., 2002), which was also confirmed from the MRT of $5.8 \pm 0.82$ hours.

In the tissue distribution studies, the homogenization time was optimized based on the organ type by keeping in mind that all the tissues will not offer the same toughness. The softer tissues require a shorter duration of homogenization, whereas tighter tissues require more time. Special care was taken during the homogenization of the tight tissues as the longer time of homogenization causes an increase in the temperature of the tissue homogenate and eventually may cause RVT degradation. To prevent the temperature rise, a chilled water jacket was used during homogenization. The RVT distribution in different tissues is shown in Figure 4 and Table 7. The tissue distribution studies showed that the RVT concentration in the liver was significantly $(p<0.05)$ high at all the time points when compared to that in the other organs. Wu et al. (2020) reported similar results, after

Table 4. Accuracy and precision of RVT in plasma and tissue homogenate samples.

\begin{tabular}{|c|c|c|c|c|c|}
\hline Analyte & RVT added in ng & $\begin{array}{c}\text { Intra-day }(n=6), \\
\text { accuracy }(\%)\end{array}$ & Precision (RSD, \%) & $\begin{array}{c}\text { Inter-day }(n=6), \\
\text { accuracy }(\%)\end{array}$ & Precision (RSD, \%) \\
\hline \multirow{3}{*}{ Plasma } & 25 & $98.52 \pm 3.57$ & 3.62 & $96.81 \pm 4.33$ & 4.47 \\
\hline & 500 & $98.16 \pm 2.41$ & 2.45 & $97.53 \pm 2.82$ & 2.89 \\
\hline & 1,000 & $96.73 \pm 3.86$ & 3.99 & $95.26 \pm 4.78$ & 5.02 \\
\hline \multirow{3}{*}{ Heart } & 25 & $102.31 \pm 5.43$ & 5.30 & $88.23 \pm 7.22$ & 8.18 \\
\hline & 500 & $99.60 \pm 4.84$ & 4.85 & $90.61 \pm 10.23$ & 11.29 \\
\hline & 1,000 & $94.32 \pm 6.32$ & 6.70 & $92.42 \pm 12.88$ & 13.94 \\
\hline \multirow{3}{*}{ Kidney } & 25 & $93.72 \pm 4.28$ & 4.56 & $87.13 \pm 16.72$ & 19.19 \\
\hline & 500 & $94.80 \pm 3.67$ & 3.87 & $89.20 \pm 8.89$ & 9.97 \\
\hline & 1,000 & $92.10 \pm 5.81$ & 6.30 & $88.79 \pm 9.34$ & 10.52 \\
\hline \multirow{3}{*}{ Liver } & 25 & $95.23 \pm 3.20$ & 3.36 & $95.87 \pm 8.61$ & 8.98 \\
\hline & 500 & $89.65 \pm 6.74$ & 7.51 & $90.65 \pm 10.60$ & 11.69 \\
\hline & 1,000 & $91.77 \pm 4.81$ & 5.24 & $90.32 \pm 6.89$ & 7.63 \\
\hline \multirow{3}{*}{ Lung } & 25 & $92.44 \pm 6.22$ & 6.72 & $89.87 \pm 5.87$ & 6.53 \\
\hline & 500 & $88.81 \pm 9.23$ & 10.36 & $86.34 \pm 6.99$ & 8.10 \\
\hline & 1,000 & $86.32 \pm 7.75$ & 8.97 & $85.19 \pm 9.26$ & 11.00 \\
\hline \multirow{3}{*}{ Spleen } & 25 & $91.80 \pm 9.38$ & 10.21 & $90.56 \pm 5.87$ & 6.49 \\
\hline & 500 & $93.64 \pm 4.70$ & 5.01 & $95.08 \pm 8.25$ & 8.68 \\
\hline & 1,000 & $89.90 \pm 7.76$ & 8.63 & $91.67 \pm 6.77$ & 7.39 \\
\hline \multirow{3}{*}{ Breast tissue } & 25 & $88.92 \pm 10.24$ & 11.51 & $89.43 \pm 9.12$ & 10.20 \\
\hline & 500 & $92.66 \pm 7.72$ & 8.33 & $88.81 \pm 8.91$ & 10.03 \\
\hline & 1,000 & $90.81 \pm 11.63$ & 12.80 & $86.54 \pm 9.82$ & 11.35 \\
\hline
\end{tabular}




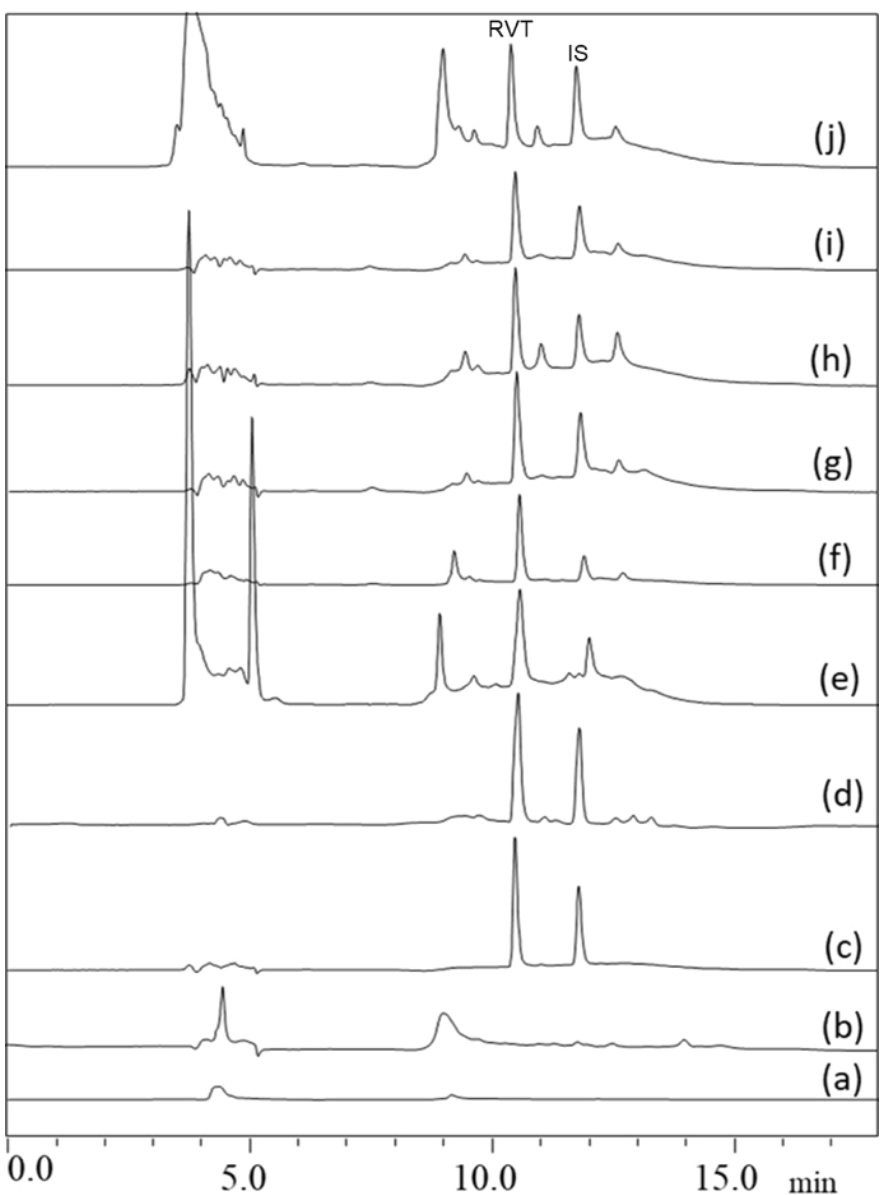

Figure 2. Specificity of the developed method showing (a) diluent, (b) plasma, (c) aqueous sample, (d) plasma sample, (e) heart, (f) kidney, (g) liver, (h) lung, (i) spleen, and (j) breast tissue.

administration of RVT through intravenous administration. The highest concentration of RVT in the liver was attained after 1 hour of RVT administration, after which the total concentration of RVT was found to decline in the liver. The RVT concentration in the breast tissue gradually increased and the highest concentration reached at 2 hours, and gradually decreased as time progressed. The distribution of drugs from the systemic circulation to tissues depends on the blood perfusion rate, cell membrane permeability, regional $\mathrm{pH}$, and tissue binding (Le,

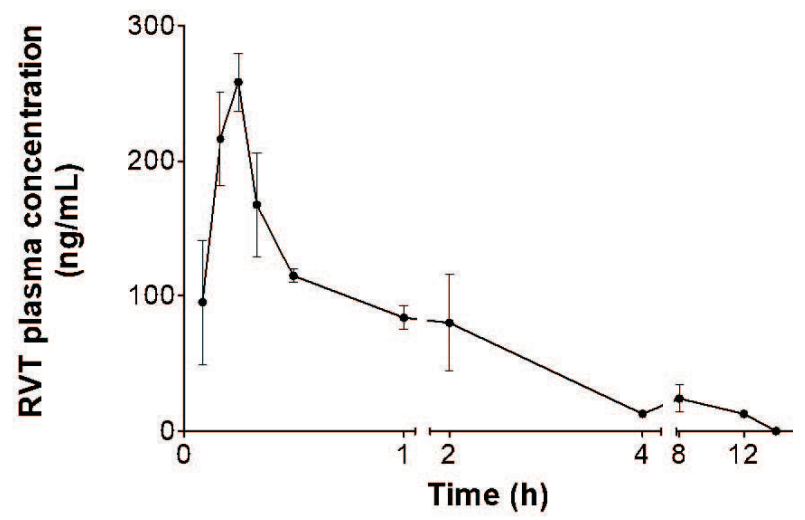

Figure 3. RVT concentration in plasma profile after single oral administration.
Table 5. Stability of RVT in different biological matrices.

\begin{tabular}{ccc}
\hline Biological matrix & Freeze-thaw stability (\% relative error) \\
\hline \multirow{2}{*}{ Plasma } & LQC & 8.46 \\
\multirow{3}{*}{ Heart } & HQC & 1.33 \\
& LQC & 7.54 \\
Kidney & HQC & 1.02 \\
& LQC & 5.31 \\
Liver & HQC & 2.78 \\
& LQC & 6.52 \\
Lung & HQC & 2.44 \\
& LQC & 7.08 \\
Spleen & HQC & 2.90 \\
& LQC & 6.99 \\
Breast tissue & HQC & 1.94 \\
& LQC & 7.01 \\
& HQC & 2.06 \\
\hline
\end{tabular}

LQC: lower quality control, HQC: higher quality control.

Table 6. Plasma pharmacokinetics parameters of RVT.

\begin{tabular}{cc}
\hline Parameters & Oral RVT \\
\hline$C_{\max }(\mathrm{ng} / \mathrm{ml})$ & $258.6 \pm 30.27$ \\
$T_{\max }($ hour $)$ & $0.3 \pm 0.00$ \\
$t_{1 / 2}($ hour $)$ & $4.4 \pm 0.12$ \\
$\mathrm{Ke}(1 /$ hour $)$ & $0.16 \pm 0.01$ \\
$\mathrm{AUC}_{0-\mathrm{t}}($ hour*ng/ml) & $450.8 \pm 18.51$ \\
$\mathrm{AUC}_{0 \text {-inf }}($ hour*ng/ml) & $532.8 \pm 29.95$ \\
$\mathrm{MRT}_{0-\mathrm{t}}($ hour $)$ & $5.8 \pm 0.82$ \\
\hline
\end{tabular}

2017). Initially, RVT was distributed in the highly perfused organs such as the liver, lung, kidney, and spleen. In the kidney, the highest RVT concentration was observed at 4 hours; as time progressed the concentration of RVT reduced. After the 12th hour following RVT administration, the concentration of RVT in plasma, as well as in different organs, was found to be very low, indicating that RVT will not accumulate in any specific organ and hence avoiding tissue damage after administration of single oral dose of $20 \mathrm{mg} / \mathrm{kg}$ in rats.

\section{CONCLUSION}

A robust, sensitive, and simple RP-HPLC method was developed and validated for the quantification of RVT in different tissues and plasma. The method offers adequate linearity, sensitivity, selectivity, and precision. The developed bioanalytical method was successfully applied for the estimation of RVT in the pharmacokinetics and tissue distribution studies in rats after the administration of RVT orally.

\section{ACKNOWLEDGMENT}

The authors are thankful to Manipal College of Pharmaceutical Sciences, Manipal, for providing the facilities to carry out this research work. 
Table 7. Distribution of RVT into different tissues after a single oral dose.

\begin{tabular}{cccccc}
\hline & \multicolumn{4}{c}{ RVT concentration (ng/g of tissue) } \\
\cline { 2 - 6 } Time (hour) & Heart & Kidney & Liver & Breast & Spleen \\
\hline 0.166 & $15.13 \pm 6.38$ & $72.02 \pm 12.11$ & $2,533.10 \pm 112.13$ & $55.69 \pm 34.98$ & $161.23 \pm 40.39$ \\
1 & $22.98 \pm 5.34$ & $623.51 \pm 57.61$ & $8,047.51 \pm 1,676.27$ & $103.46 \pm 52.32$ & $435.50 \pm 156.57$ \\
2 & $15.75 \pm 6.75$ & $777.68 \pm 131.53$ & $4,191.55 \pm 752.18$ & $259.13 \pm 67.59$ & $413.35 \pm 48.23$ \\
4 & $268.41 \pm 42.24$ & $814.79 \pm 251.58$ & $6,565.59 \pm 538.64$ & $86.28 \pm 16.22$ & $454.20 \pm 77.46$ \\
8 & $7.50 \pm 10.61$ & $141.22 \pm 27.99$ & $2,314.02 \pm 539.79$ & 0 & $190.25 \pm 51.49$ \\
12 & 0.00 & $7.38 \pm 15.24$ & $61.44 \pm 10.19$ & $31.72 \pm 9.05$ & 0 \\
\hline
\end{tabular}

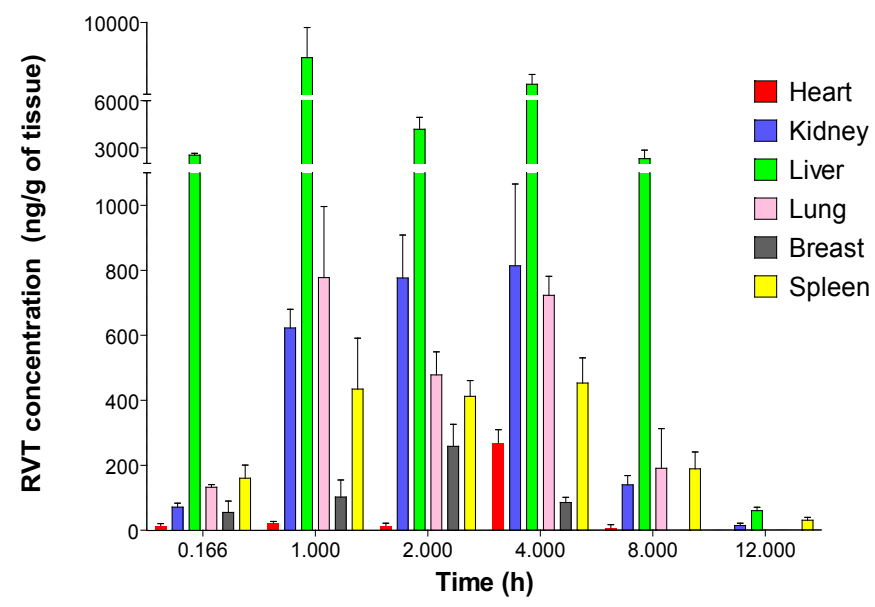

Figure 4. RVT tissues distribution profile into different tissues after a single oral dose.

\section{CONFLICT OF INTEREST}

The authors declare no conflict of interest.

\section{FUNDING}

This work was supported by the Science and Engineering Research Board, Dept. of Science and Technology, New Delhi, India (Ref. No. EMR/2016/007006).

\section{AUTHOR CONTRIBUTIONS}

All authors made substantial contributions to conception and design, acquisition of data, or analysis and interpretation of data; took part in drafting the article or revising it critically for important intellectual content; agreed to submit to the current journal; gave final approval of the version to be published; and agree to be accountable for all aspects of the work. All the authors are eligible to be an author as per the international committee of medical journal editors (ICMJE) requirements/guidelines.

\section{ETHICAL APPROVALS}

Ethical approval was taken from the Institutional Animal Ethical Committee, Kasturba Medical College, Manipal, India (Approval no.: IAEC/KMC/33/2017) before the study and Committee for the Purpose of Control and Supervision of Experiments on Animals guidelines were followed during the studies.

\section{DATA AVAILABILITY}

All data generated and analyzed are included within this research article.

\section{PUBLISHER'S NOTE}

This journal remains neutral with regard to jurisdictional claims in published institutional affiliation.

\section{REFERENCES}

Aguwa US, Eze CE, Obinwa BN, Okeke SN, Onwuelingo SF, Okonkwo DI, Ogbuokiri DK, Agulanna AE, Obiesie IJ, Umezulike AJ. Comparing the Effect of methods of rat euthanasia on the brain of wistar rats: cervical dislocation, chloroform inhalation, diethyl ether inhalation and formalin inhalation. J Adv Med Med Res, 2020; 32(17):8-16.

Plate AYA, Crankshaw DL, Gallaher DD. The effect of anesthesia by diethyl ether or isoflurane on activity of cytochrome P450 2E1 and P450 reductases in rat liver. Anesth Analg, 2005; 101(4):1063-4.

Bertelli AAE, Giovannini L, Stradi R, Bertelli A, Tillement JP. Plasma, urine and tissue levels of trans- and cis-resveratrol (3,4',5-trihydroxystilbene) after short-term or prolonged administration of red wine to rats. Int J Tissue React, 1996; 18(2-3):67-71.

Bishayee A. Cancer prevention and treatment with resveratrol: from rodent studies to clinical trials. Cancer Prev Res, 2009; 2(5):409-18.

Emília JM, Monica M, Joana M, Planas. Quantification of transresveratrol and its metabolites in rat plasma and tissues by HPLC. J. Pharm. Biomed, 2010; 51(2):391-398.

Ethemoglu MS, Seker FB, Akkaya H, Kilic E, Aslan I, Erdogan CS, Yilmaz B. Anticonvulsant activity of resveratrol-loaded liposomes in vivo. Neuroscience, 2017; 357:12-9.

FDA, CDER, CVM. Bioanalytical method validation guidance for industry biopharmaceutics bioanalytical method validation guidance for industry biopharmaceutics contains nonbinding recommendations [Online].2018.Availableviahttp://www.fda.gov/Drugs/GuidanceCompliance RegulatoryInformation/Guidances/default.htmand/orhttp://www.fda.gov/ AnimalVeterinary/GuidanceComplianceEnforcement/GuidanceforIndustry/ default.htm (Accessed 10 July 2021).

Fiod Riccio BV, Fonseca-Santos B, Colerato Ferrari P, Chorilli M. Characteristics, biological properties and analytical methods of transresveratrol: a review. Crit Rev Anal Chem, 2020; 50(4):339-58.

Jagwani S, Jalalpure S, Dhamecha D, Hua GS, Jadhav K. Development and validation of reverse-phase high-performance liquid chromatographic method for determination of resveratrol in human and rat plasma for preclinical and clinical studies. Indian J Pharm Educ Res, 2020; 54(1):187-93.

Juan ME, Alfaras I, Planas JM. Determination of dihydroresveratrol in rat plasma by HPLC. J Agric Food Chem, 2010a; 58(12):7472-5.

Juan ME, Maijó M, Planas JM. Quantification of transresveratrol and its metabolites in rat plasma and tissues by HPLC. J Pharm Biomed Anal, 2010b; 51(2):391-8. 
Kapetanovic IM, Muzzio M, Huang Z, Thompson TN, McCormick DL. Pharmacokinetics, oral bioavailability, and metabolic profile of resveratrol and its dimethylether analog, pterostilbene, in rats. Cancer Chemother Pharmacol, 2011; 68(3):593.

Le J. Drug distribution to tissues - clinical pharmacology. MSD Manual Professional Edition, MSD Manual [Online]. 2017. Available via https://www.msdmanuals.com/professional/clinical-pharmacology/ pharmacokinetics/drug-distribution-to-tissues (Accessed 10 July 2021).

Lin H, Lin L, Xu L, Xie Y, Xia Z, Wu Q. Liquid-liquid extraction pretreatment samples method used for pharmacokinetic study of rhubarb in rats after oral administrated. J Tradit Chin Med Sci, 2018; 5(3):291-301.

Marier JF, Vachon P, Gritsas A, Zhang J, Moreau JP, Ducharme MP. Metabolism and disposition of resveratrol in rats: extent of absorption, glucuronidation, and enterohepatic recirculation evidenced by a linked-rat model. J Pharmacol Exp Ther, 2002; 302(1):369-73.

Ndiaye M, Philippe C, Mukhtar H, Ahmad N. The grape antioxidant resveratrol for skin disorders: promise, prospects, and challenges. Arch Biochem Biophys, 2011; 508(2):164-70.

Salehi B, Mishra AP, Nigam M, Sener B, Kilic M, Sharifi-Rad M, Fokou PVT, Martins N, Sharifi-Rad J. Resveratrol: a double-edged sword in health benefits. Biomedicines, 2018; 6(3):91.

Sanson AL, Silva SCR, Martins MCG, Giusti-Paiva A, Maia PP, Martins I. Liquid-liquid extraction combined with high performance liquid chromatography-diode array-ultra-violet for simultaneous determination of antineoplastic drugs in plasma. Brazil J Pharm Sci, 2011; 47(2):363-71.

Santos AC, Veiga FJ, Sequeira JAD, Fortuna A, Falcão A, Pereira I, Pattekari P, Fontes-Ribeiro C, Ribeiro AJ. First-time oral administration of resveratrol-loaded layer-by-layer nanoparticles to rats-a pharmacokinetics study. Analyst, 2019; 144(6):2062-79.
Sinha D, Sarkar N, Biswas J, Bishayee A. Resveratrol for breast cancer prevention and therapy: preclinical evidence and molecular mechanisms. Semin Cancer Biol, 2016; 40-41:209-32.

Szkudelska K, Nogowski L, Szkudelski T. Adipocyte dysfunction in rats with streptozotocin-nicotinamide-induced diabetes. Int J Exp Pathol, 2014; 95(2):86-94.

Wu M, Zhong C, Deng Y, Zhang Q, Zhang X, Zhao X. Resveratrol loaded glycyrrhizic acid-conjugated human serum albumin nanoparticles for tail vein injection II: pharmacokinetics, tissue distribution and bioavailability. Drug Deliv, 2020; 27(1):81-90.

PubChem. Resveratrol $\mid \mathrm{C}_{14} \mathrm{H}_{12} \mathrm{O}_{3}$. 2021. Available via https:// pubchem.ncbi.nlm.nih.gov/compound/Resveratrol\#section=DissociationConstants\&fullscreen=true (Accessed 10 July 2021)

\section{How to cite this article:}

Gadag S, Narayan R, Nayak Y, Nayak UY. Bioanalytical RPHPLC method validation for resveratrol and its application to pharmacokinetic and drug distribution studies. J Appl Pharm Sci, 2022; 12(02):158-164. 